\title{
The prevalence of excessive weight in Balearic Islands' young and middle-aged women and its association with social and socioeconomic factors: a ten-year trend (2000-2010)
}

\author{
Josep LI. Coll ${ }^{1}$, Maria del Mar Bibiloni', Rogelio Salas ${ }^{2}$, Antoni Pons ${ }^{1}$ and Josep A. Tur ${ }^{1 *}$
}

\begin{abstract}
Background: Knowledge about trends in the socioeconomic patterning of overweight and obesity in women provides insights into the nature of the obesity epidemic. Therefore the aim was to assess a ten-year trend (2000-2010) in the prevalence of excessive weight in Balearic Islands' women and its association with socioeconomic factors.

Method: Young (18-35 year-old) and middle-aged (36-55 year-old) women were selected from two population-based cross-sectional nutritional surveys carried out in the Balearic Islands, Spain. The participation rate was $80 \%$ during 1999-2000 and $92.5 \%$ during 2009-2010. Measured weight and height was obtained, and body mass index $\left(\mathrm{kg} / \mathrm{m}^{2}\right)$ was classified as follows: overweight $(25.0<30)$, obese $(\geq 30)$ and excessive weight ( $\geq 25$ ). In both surveys, a general questionnaire including questions relating to socioeconomic status factors was used. Logistic regression was used to examine the association of excessive weight with socioeconomic variables and to test the interaction between the survey period and the socioeconomic factors.

Results: Overall, while the prevalence of obesity mainly remained stable over the study period, the prevalence of overweight increased from 21.0 to $24.8 \%$. Young women showed an increased prevalence of overweight and excessive weight, from 14.1 to $20.9 \%$ and from 20.9 to $28.6 \%$, respectively. Significant differences were not found in middle-aged women. Over the whole period, the incidence of excessive weight was higher among middle-aged and foreign women, but lower in women with a high educational profile and in employment. The prevalence of excessive weight in young women was also around 2.5 times higher in women who were living with at least one child at home. The tendency towards excessive weight in employed women decreased significantly between 2000 and 2010 in the younger age group (OR: 0.42; 95 \% Cl: 0.22-0.82).

Conclusions: No significant increase in the prevalence of overweight/obesity was observed in middle-aged women, with a low level of education being the single socioeconomic variable associated with excessive weight in this target group. Overweight/obesity increased in young women with unemployment being the distinguishing socioeconomic factor associated with this increase.
\end{abstract}

\footnotetext{
*Correspondence: pep.tur@uib.es

'Research Group on Community Nutrition and Oxidative Stress, University of

Balearic Islands, IdISPa, and CIBEROBN (Physiopathology of Obesity and

Nutrition CB12/03/30038), Guillem Colom Bldg, Campus, E-07122 Palma de

Mallorca, Spain

Full list of author information is available at the end of the article
} 


\section{Background}

Despite some signs suggesting that overweight and obesity are levelling off [1], it is a pandemic situation that poses one of the most serious public health challenges of the 21st century [2]. Decreasing quality of life [3, 4], rising serious chronic diseases (hypertension, diabetes, hypercholesterolemia, asthma, etc.) $[5,6]$ and predisposition to certain infections [7] are all associated with increased excessive weight (overweight + obesity). In addition, excessive weight also has financial consequences [8, 9]. For example, in 2008, the cost of obesity in the USA was estimated at around US\$147 billion [10].

Socioeconomic factors have changed over time and, while obesity levels have been rising in all socioeconomic groups, some groups are more affected than others. Whereas, in the past, obesity was a disease of affluence, in recent decades it has been seen more frequently in lower socioeconomic groups [11], firstly in developed countries and afterwards in developing countries [12]. In this respect a consistent relationship between lower socioeconomic status and obesity has frequently been found in women [13]. Therefore, knowledge about trends in the socioeconomic patterning of overweight and obesity in women over time provides us with insights into the nature of the obesity epidemic.

In line with the remarkable socioeconomic changes observed in Europe over the first decade of the $21^{\text {st }}$ century, the Balearic Islands, an archipelago off the East Coast of Spain, has also been affected by cultural changes, the development of tourism, high population growth and an increase in immigration [14]. Persistent income-related problems with obesity have been reported in Spain [15], although the contribution of education has been considered to be the main socioeconomic variable explaining the prevalence of obesity [16]. It was pointed out recently that a country's level of economic development changes the relationship between educational attainment and obesity, with stronger social patterning in women [17]. In Spain women showed a higher prevalence of obesity over time, but income-related inequalities were similar for both men and women in 1987. By 2006 figures remained relatively stable in men, whereas the inequality had tripled in women [18]. Therefore the aim of this study was to assess a ten-year trend (2000-2010) in the prevalence of excessive weight in Balearic Islands' women and its association with socioeconomic factors (i.e. age, educational profile, professional profile, origin, cohabitation and living with at least one child at home).

\section{Methods}

\section{Study design}

The study was based on two population-based crosssectional nutritional surveys carried out in the Balearic Islands, Spain (2000-2010).

\section{Study population, recruitment and approval}

This study is part of the Balearic Islands' Nutritional Survey (ENIB survey, 1999-2000) and the "Prevalence of Obesity in the Balearic Islands: their relationship with oxidative stress and inflammatory mediators" study (OBEX survey, 2009-2010). The ENIB and OBEX surveys were designed to obtain information on the health and nutritional status of the resident population in the Balearics [19-22]. In both surveys, the target population consisted of all inhabitants of the Balearic Islands aged between 16 and 65 years old. The population samples were taken from residents registered on the Balearic Islands' official population census. The sampling techniques included stratification according to geographical area and municipality size, inhabitants' age and gender and randomisation into subgroups, with the primary sampling units being Balearic municipal districts and individuals within these municipalities making up the final sample units.

\section{Sample selection}

This analysis was limited to young (18-35 year-old) and middle-aged (36-55 year-old) women living in the Balearics with no missing data needed to calculate their body mass index $\left(\mathrm{BMI}, \mathrm{kg} / \mathrm{m}^{2}\right)$. The participation rate was $80 \%$ during 1999-2000 and 92.5 \% during 2009-2010. Non-participation rates included potential subjects who declined to be interviewed (particularly over-55's) as well as involuntary non-participants who were excluded due to unavoidable constraints on them taking part.

These sample sizes were considered sufficient to detect risk factors at regional level with $95 \%$ confidence and a precision rate of 3.3 and $3.9 \%$, respectively. These sample sizes also calculated prevalence with $95 \%$ confidence and a precision rate of 4.3 and $5.3 \%$ in the young $(n=512)$ and middle-aged $(n=342)$ population in 19992000 , respectively, and 5.0 and $6.2 \%$ in the young $(n=378)$ and middle-aged $(n=252)$ in 2009-2010, respectively.

\section{Ethics}

The study was conducted according to the guidelines laid down in the Declaration of Helsinki and all procedures were approved by the Balearic Islands Ethics Committee (approval reference numbers IB/135/98/PI and IB/1128/09/PI). Written informed consent was obtained from all subjects.

\section{Anthropometric measurements}

Anthropometric measurements were performed by welltrained observers in order to avoid inter-observer coefficients of variation. Height was determined using a mobile anthropometer (Kawe 44444, Asperg, Germany) to the nearest millimetre, with the subject's head in the Frankfurt plane. Body weight was determined to the nearest 100 g using a digital scale (Tefal, sc9210, 
Rumilly, France). Women were weighed in bare feet and light clothes, noting and subtracting the weight of the clothes. Weight and height measurements were used to calculate body mass index $\left(\mathrm{BMI}, \mathrm{kg} / \mathrm{m}^{2}\right)$. Overweight, obesity and excessive weight were defined as BMI 25.0$29.9 \mathrm{~kg} / \mathrm{m}^{2}, \geq 30 \mathrm{~kg} / \mathrm{m}^{2}$, and $\geq 25.0 \mathrm{~kg} / \mathrm{m}^{2}$, respectively [2].

\section{Socioeconomic determinants}

In both surveys, a questionnaire including the following questions was used: age, region of origin (defined as being born in the Balearic Islands, the East of Spain as defined by the Mediterranean coast, other parts of Spain and other countries (in the OBEX survey the specific country was also included)), marital status (single, married, divorced, widowed and also "separated" in the OBEX survey), subjects living at home, educational profile (grouped according to years and type of education: low, $<6$ years at school; medium, 6 to 12 years' education; high, 12 years' education), and professional profile. The respondents were grouped into binary categories as follows: age group (young adults, 18-35 year-olds; middle-aged adults, 36-55 year-olds); origin (Spain; other countries); cohabitation (living alone, married or cohabiting); living with at least one child at home (none; yes); educational profile (low (including medium), i.e. $\leq 12$ years of education; high, >12 years of education); and professional profile (unemployed, including student and homemaker; employed).

\section{Statistics}

Analyses were performed with the SPSS statistical software package version 21.0 (SPSS Inc., Chicago, IL, USA). Significant differences in prevalence were calculated by means of $X^{2}$. Differences between group means were tested by an unpaired Students' $t$-test. Logistic regression models with calculations of the corresponding odds ratio (OR) and a $95 \%$ confidence interval (CI) were used to examine the possible association between socioeconomic factors (independent variables) and excessive weight (dependent variables). Binomial logistic regression analyses adjusted by age were first carried out for each socioeconomic variable and survey period. Binomial logistic regression analyses were also carried out for the prevalence of excessive weight including the socioeconomic variable, age (continuous variable), survey period and interaction between the two survey periods and the socioeconomic variable in order to examine the difference in prevalence between socioeconomic variables across time. The level of significance for acceptance was $P<0.05$.

\section{Results}

This study included 512 young (18-35 year-old) and 342 middle-aged (36-55 year-old) women living in the Balearics interviewed in the ENIB survey (1999-2000), and 378 young and 252 middle-aged women interviewed in the OBEX survey (2009-2010). Results revealed differences between the two surveys when it came to origin, educational profile, professional profile, cohabitation and living with at least one child (Table 1). Over the past decade an increase in the proportion of non-Spanish women living alone, with no children at home, with a high level of education and a job was observed. However, the rising proportion of women living alone and in employment was only shown in the middle-aged group. No significant changes were observed in the height of young women, but middle-aged women were noted to be taller. The prevalence of obesity mainly remained stable over the study period, but the prevalence of overweight increased from 21.0 to $24.8 \%$. Overweight and excessive weight also increased in young women, from 14.1 to $20.9 \%$ and from 20.9 to $28.6 \%$, respectively. No statistically significant changes were found in the middle-aged group.

In both surveys, adjusted analysis with socioeconomic variables (Table 2) showed an increased risk of excessive weight in middle-aged and non-Spanish women and a decreased risk in women with a high educational profile. In 2009-2010, the prevalence of excessive weight was also 0.5 times lower amongst women in employment. In young women (Table 3 ), the prevalence was around 2.5 times higher in women who were living with at least one child at home. Educational profile was the only socioeconomic variable associated with the risk of excessive weight or obesity in middle-aged women (Table 4). Overall, the probability of being overweight decreased significantly between 2000 and 2010 in both middleaged and employed women. However, the association with employment only decreased significantly in the younger group.

\section{Discussion}

The general findings of this study are as follows. Firstly, over the past decade the female population in the Balearic Islands has undergone social and socioeconomic changes, with an increase in the proportion of nonSpanish women, an increase in women living alone particularly in the middle-aged group-, with no children at home, with a high educational profile and also in employment, with the latter being particularly noticeable in the middle-aged group. Secondly, in line with these social and socioeconomic changes the overall prevalence of overweight increased. An increased prevalence in overweight and excessive weight was observed in young women, although no changes were seen in the middleaged group. Thirdly, in both surveys the overall risk of excessive weight was associated with age, origin, educational profile and also the likelihood of having a job in 2009-2010. Living with at least one child at home was 
Table 1 Characteristics of the subjects ${ }^{a, b}$

\begin{tabular}{|c|c|c|c|c|c|c|}
\hline & \multicolumn{3}{|c|}{ 1999-2000 (ENIB survey) } & \multicolumn{3}{|c|}{ 2009-2010 (OBEX survey) } \\
\hline & All & $18-35$ & $36-55$ & All & $18-35$ & $36-55$ \\
\hline$n$ & 854 & 512 & 342 & 630 & 378 & 252 \\
\hline Weight $(\mathrm{kg})^{\mathrm{c}}$ & $62.1 \pm 11.5$ & $60.2 \pm 11.0$ & $65.0 \pm 11.6$ & $64.2 \pm 11.9^{* *}$ & $62.4 \pm 12.4^{* *}$ & $66.9 \pm 13.3^{\mathrm{NS}}$ \\
\hline Height $(\mathrm{cm})^{c}$ & $161.3 \pm 6.6$ & $162.9 \pm 6.1$ & $159.0 \pm 6.6$ & $161.6 \pm 6.4^{\mathrm{NS}}$ & $162.1 \pm 6.4^{\mathrm{NS}}$ & $160.9 \pm 6.5^{* * *}$ \\
\hline BMI $\left(\mathrm{kg} / \mathrm{m}^{2}\right)^{\mathrm{c}}$ & $23.9 \pm 4.5$ & $25.7 \pm 4.5$ & $22.7 \pm 4.1$ & $24.6 \pm 4.9^{* *}$ & $25.9 \pm 5.2^{\mathrm{NS}}$ & $23.7 \pm 4.4^{* * *}$ \\
\hline Prevalence of overweight (\%) ${ }^{d}$ & 21.0 & 14.1 & 31.3 & $24.8^{*}$ & $20.9^{* *}$ & $30.6^{\mathrm{NS}}$ \\
\hline Prevalence of obesity (\%) $^{d}$ & 11.1 & 6.8 & 17.5 & $11.0^{\mathrm{NS}}$ & $7.7^{\mathrm{NS}}$ & $15.9^{\mathrm{NS}}$ \\
\hline Prevalence of excessive weight ${ }^{1}(\%)^{d}$ & 32.1 & 20.9 & 48.8 & $35.7^{\mathrm{NS}}$ & $28.6^{* *}$ & $46.4^{\mathrm{NS}}$ \\
\hline \multicolumn{7}{|l|}{ Origin (\%) } \\
\hline Spanish & 95.0 & 96.5 & 92.7 & $84.9^{* * *}$ & $82.7^{* * *}$ & $88.3^{*}$ \\
\hline Non-Spanish & 5.0 & 3.5 & 7.3 & 15.1 & 17.3 & 11.7 \\
\hline \multicolumn{7}{|l|}{ Cohabitation (\%) $^{d}$} \\
\hline Living alone & 37.0 & 58.2 & 5.3 & $42.7^{*}$ & $62.9^{\mathrm{NS}}$ & $12.4^{* *}$ \\
\hline Married or cohabiting & 63.0 & 41.8 & 94.7 & 57.3 & 37.1 & 87.6 \\
\hline \multicolumn{7}{|c|}{ Living with at least one child at home (\%) ${ }^{d}$} \\
\hline None & 51.2 & 70.9 & 21.6 & $63.8^{* * *}$ & $84.6^{* * *}$ & $32.7^{* *}$ \\
\hline Yes & 48.8 & 29.1 & 78.4 & 36.2 & 15.4 & 67.3 \\
\hline \multicolumn{7}{|l|}{ Educational profile (\%) } \\
\hline Low (including medium) & 76.5 & 67.9 & 89.8 & $58.0^{* * *}$ & $58.9^{* *}$ & $56.6^{* * *}$ \\
\hline High & 23.5 & 32.1 & 10.2 & 42.0 & 41.1 & 43.4 \\
\hline \multicolumn{7}{|l|}{ Professional profile (\%) ${ }^{d}$} \\
\hline Unemployed & 40.5 & 39.1 & 42.8 & $28.8^{* * *}$ & $38.1^{\mathrm{NS}}$ & $14.9^{* * *}$ \\
\hline Employed & 59.5 & 60.9 & 57.3 & 71.2 & 61.9 & 85.1 \\
\hline
\end{tabular}

BMI body mass index, NS not significant

aPrevalence of overweight: $\mathrm{BMI} \geq 25-<30 \mathrm{~kg} / \mathrm{m}^{2}$; obesity: $\geq 30 \mathrm{~kg} / \mathrm{m}^{2}$; excessive weight: $\mathrm{BMI} \geq 25 \mathrm{~kg} / \mathrm{m}^{2}$

${ }^{b}$ Data were expressed as ' $m e a n \pm$ standard deviation and ${ }^{\mathrm{d}}$ prevalence (\%). Differences between surveys were tested by ${ }^{\mathrm{c}}$ unpaired Students' $\mathrm{t}$-test and ${ }^{\mathrm{d}} \mathrm{X}^{2}$ :

${ }^{*} P<0.05,{ }^{* *} P<0.01,{ }^{* * *} P<0.001$

also associated with the risk of excessive weight in young women and a low educational profile was the only identified risk factor in middle-aged women. Finally, the probability of middle-aged employed women having excessive weight decreased significantly over time.

Worldwide, the age-standardised prevalence of excessive weight increased from $24.6 \%$ (95 \% uncertainty interval (UI): $22.7-26.7 \%$ ) in 1980 to $34.4 \%$ (95\% UI: $33.2-35.5 \%)$ in 2008 [23]. Moreover, age-standardised obesity prevalence nearly doubled from $6.4 \%$ (95 \% UI: $5.7-7.2)$ to $12.0 \%$ (95 \% UI: $11.5-12.5$ ) during the same 28 year period [23]. Half of this change occurred during the 1980-2000 period and the other half occurred during 2000-2008 [23]. The regions with reported increases in the prevalence of obesity were Central Latin America, South Latin America and Oceania [23]. In women, the worldwide proportion with excessive weight increased from $29.8 \%$ (95 \% UI: 29.3-30.2) in 1980 to $38.0 \%$ (UI: $37.5-38.5 \%)$ in 2013 [24]. In 1990, more than $50 \%$ of women had excessive weight in 47 countries, a figure that increased to 74 in 2000 and to 101 in 2008 [23]. In Europe, over the 2000-2009 period, obesity and excessive weight in adult women ranged between 13.3 and 30.0 and 31.0 and $53.2 \%$, respectively [25]. Our results back up the results of a previous Spanish study that revealed an increased prevalence in excessive weight of $10.3 \%$ among women over the 19872007 period [26]. Nevertheless, contrary to Spanish literature [27] which positioned Spain as one of the countries where the occurrence of obesity has risen most substantially, our results did not reveal an increased prevalence of obesity in young and middleaged women.

Increased BMI is associated with age [28, 29], with the greatest weight gain occurring between the ages of 20 and 40 [24]. Young women showed the largest rising occurrence of excessive weight, which agrees with previous studies [30, 31]. Howel [32] described trends (1999-2006) in the prevalence of obesity and 
Table 2 Global results of binomial regressions of excessive weight prevalence by social and socioeconomic factors and survey period in Balearic Islands' women ${ }^{\mathrm{a}, \mathrm{b}, \mathrm{c}}$

\begin{tabular}{|c|c|c|c|c|c|c|}
\hline & \multicolumn{2}{|c|}{ 1999-2000 (ENIB survey) } & \multicolumn{2}{|c|}{ 2000-2010 (OBEX survey) } & \multirow[b]{2}{*}{ Change in Prevalence $(\%)^{c}$} & \multirow[b]{2}{*}{$\begin{array}{l}P \text {-value for } \\
\text { interaction }\end{array}$} \\
\hline & $\mathrm{BMI} \geq 25 n(\%)$ & Adjusted OR $(95 \%$ Cl) & $\mathrm{BMI} \geq 25 n(\%)$ & Adjusted OR $(95 \%$ Cl) & & \\
\hline$n$ & $274(32.1)$ & & 225 & & & \\
\hline \multicolumn{7}{|l|}{ Age group } \\
\hline 18-35 years & $107(39.1)$ & 1.00 (ref.) & $108(48.0)$ & 1.00 (ref.) & 1.00 (ref.) & \\
\hline $36-55$ years & $167(60.9)$ & $3.61(2.67,4.88)^{* * *}$ & $117(52.0)$ & $2.16(1.55,3.02)^{* * *}$ & $0.60(0.38,0.94)$ & 0.026 \\
\hline \multicolumn{7}{|l|}{ Educational profile } \\
\hline Low (including medium) & $246(89.7)$ & 1.00 (ref.) & $149(66.1)$ & 1.00 (ref.) & 1.00 (ref.) & \\
\hline High & $28(10.3)$ & $0.42(0.27,0.66)^{* * *}$ & $76(33.9)$ & $0.52(0.37,0.75)^{* * *}$ & $1.26(0.71,2.24)$ & 0.436 \\
\hline \multicolumn{7}{|l|}{ Professional profile } \\
\hline Unemployed & $117(42.7)$ & 1.00 (ref.) & 69 (30.6) & 1.00 (ref.) & 1.00 (ref.) & \\
\hline Employed & $157(57.3)$ & $0.88(0.64,1.20)$ & $156(69.4)$ & $0.50(0.33,0.76)^{* *}$ & $0.56(0.34,0.92)$ & 0.022 \\
\hline \multicolumn{7}{|l|}{ Origin } \\
\hline Spanish & $255(93.1)$ & 1.00 (ref.) & $181(80.4)$ & 1.00 (ref.) & 1.00 (ref.) & \\
\hline Non-Spanish & $19(6.9)$ & $1.07(1.05,1.08)^{* * * *}$ & 44 (19.6) & $1.06(1.04,1.07)^{* * *}$ & $1.53(0.69,3.40)$ & 0.297 \\
\hline \multicolumn{7}{|l|}{ Cohabitation } \\
\hline Living alone & $60(21.9)$ & 1.00 (ref.) & $73(32.4)$ & 1.00 (ref.) & 1.00 (ref.) & \\
\hline Married or cohabiting & $214(78.1)$ & $1.03(0.67,1.59)$ & $152(67.6)$ & $1.05(0.69,1.59)$ & $0.83(0.51,1.36)$ & 0.465 \\
\hline \multicolumn{7}{|c|}{ Living with at least one child at home } \\
\hline None & $101(36.9)$ & 1.00 (ref.) & $121(53.8)$ & 1.00 (ref.) & 1.00 (ref.) & \\
\hline Yes & $173(63.1)$ & $1.15(0.81,1.63)$ & $104(46.2)$ & $1.15(0.77,1.70)$ & $0.86(0.54,1.36)$ & 0.519 \\
\hline
\end{tabular}

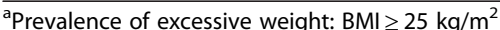

${ }^{\mathrm{b}}$ Binomial logistic regression analysis adjusted by age. ${ }^{*} P<0.05,{ }^{* *} P<0.01,{ }^{* *} P<0.001$

'Binomial logistic regression analysis adjusted by age (continuous) including the social and socioeconomic factors, survey periods and the interaction between the survey periods and the socioeconomic factor. ${ }^{*} P<0.05,{ }^{* *} P<0.01,{ }^{* * *} P<0.001$

overweight in English adults and also found that when the subjects were divided into 10-year pseudo-birth-cohorts, the prevalence of obesity and overweight was consistently higher at a given average age for pseudo-cohorts born more recently.

Furthermore, to our knowledge, few studies have determined trends in excessive weight by evaluating its association with socioeconomic factors [33, 34]. Moreover, controversial results have been found in literature due to differences in the anthropometric measurements used (i.e. self-reported vs. measured data), socioeconomic indicators, time periods and/or statistical analysis [11].

\section{Educational profile}

In Western societies an inverse relationship between educational profile and excessive weight has been shown many times, especially amongst women [13]. A comparative appraisal of educational inequalities in overweight and obese adults in 19 European countries found the largest educational inequalities in Mediterranean women [35]. Overweight and/or obesity increases have also been associated with low levels of education in Swiss men and women [34], English women [11] and USA men [36]. An increase in the proportion of obesity in Spanish women associated with a low level of education was also reported between 1987 and 1997 [37]. Spanish people with a lower educational profile showed lower energy intake [38], just as women with a lower educational profile showed sedentary behaviour during their leisure time [39].

\section{Employment status}

Previous studies have also associated unemployment with poor health [40-42] such as obesity [43], mortality from cardiovascular diseases [44] and infectious diseases [45]. However, few studies have investigated trends in excessive weight according to occupational profile $[46,47]$. Knowledge about trends in excessive weight for women from different occupational profiles provides us with insights into the nature of obesity [48]. The occupational transition undergone by women, from unemployed status to the various current professional profiles (agriculture-production, clerical, services and 
Table 3 Results of binomial regressions of excessive weight prevalence by social and socioeconomic factors and survey period in young Balearic Islands' women (18-35 years-old) ${ }^{a, b, c}$

\begin{tabular}{|c|c|c|c|c|c|c|}
\hline & \multicolumn{2}{|c|}{ 1999-2000 (ENIB survey) } & \multicolumn{2}{|c|}{ 2000-2010 (OBEX survey) } & \multirow[b]{2}{*}{ Change in Prevalence (\%) } & \multirow[b]{2}{*}{$\begin{array}{l}P \text {-value for } \\
\text { interaction }\end{array}$} \\
\hline & $\mathrm{BMI} \geq 25 n(\%)$ & Adjusted OR (95\% Cl) & $\mathrm{BMI} \geq 25 n(\%)$ & Adjusted OR (95\% Cl) & & \\
\hline$n$ & $107(20.9)$ & & $108(28.6)$ & & & \\
\hline \multicolumn{7}{|l|}{ Educational profile } \\
\hline Low (including medium) & $88(81.9)$ & 1.00 (ref.) & $70(64.8)$ & 1.00 (ref.) & 1.00 (ref.) & \\
\hline High & $19(18.1)$ & $0.43(0.25,0.74)^{* *}$ & $38(35.2)$ & $0.47(0.28,0.78)^{* *}$ & $1.17(0.56,2.46)$ & 0.682 \\
\hline \multicolumn{7}{|l|}{ Professional profile } \\
\hline Unemployed & $32(29.9)$ & 1.00 (ref.) & $48(44.3)$ & 1.00 (ref.) & 1.00 (ref.) & \\
\hline Employed & $75(70.1)$ & $1.25(0.74,2.09)$ & $60(55.7)$ & $0.45(0.27,0.77)^{* *}$ & $0.42(0.22,0.82)$ & 0.010 \\
\hline \multicolumn{7}{|l|}{ Origin } \\
\hline Spanish & $100(93.5)$ & 1.00 (ref.) & $81(75.0)$ & 1.00 (ref.) & 1.00 (ref.) & \\
\hline Non-Spanish & $7(6.5)$ & $2.06(0.77,5.51)$ & $27(25.0)$ & $2.15(1.21,3.82)^{* *}$ & $1.05(0.34,3.27)$ & 0.938 \\
\hline \multicolumn{7}{|l|}{ Cohabitation } \\
\hline Living alone & $50(46.7)$ & 1.00 (ref.) & $61(56.5)$ & 1.00 (ref.) & 1.00 (ref.) & \\
\hline Married or cohabiting & $57(53.3)$ & $1.26(0.70,2.27)$ & $47(43.5)$ & $1.13(0.67,1.88)$ & $0.91(0.48,1.72)$ & 0.774 \\
\hline \multicolumn{7}{|c|}{ Living with at least one child at home } \\
\hline None & $58(54.2)$ & 1.00 (ref.) & $241(73.1)$ & 1.00 (ref.) & 1.00 (ref.) & \\
\hline Yes & $49(45.8)$ & $2.40(1.28,4.52)^{* *}$ & $29(26.9)$ & $2.56(1.39,4.71)^{* *}$ & $1.27(0.61,2.64)$ & 0.526 \\
\hline
\end{tabular}

management), is associated with a lower excessive weight prevalence [46]. However, the international financial crisis, which emerged in full force after September 2008, had a hugely negative impact on Spain where there was a large increase in unemployment. It is estimated that 1.02 million young adults aged between 20 and 34 were inactive in the last quarter of 2010 [49]. At present, in the first quarter of 2015, 0.96 million young adults were still inactive and this figure may have decreased to 0.73 million [49]. Nevertheless, in recent years, time spent in education has increased in Spain. In 2000 some $23 \%$ of $25-64$ year-olds and $34 \%$ of $25-34$ yearolds were enrolled in tertiary education and by 2011, $32 \%$ of $25-64$ year-olds and $39 \%$ of $25-34$ year-olds were enrolled in tertiary education [50]. The percentage of young people (15-29 year-olds) not in employment but in tertiary level education also increased from 12.7 in 2008 to $21.4 \%$ in 2011, which suggests that some young Spaniards see education as a temporary way out of unemployment and a potential advantage when they try to get back into employment at a later stage [50]. Our results suggest that there may have been an increase in BMI differences between employed and unemployed young adults; however, further research focussing on this possible relationship is needed.

\section{Origin}

Traditionally Spain was an emigrant country and only became a host country during the last century. Specifically, in the Balearic Islands, the number of people from abroad has increased by 228.7 \% (i.e. 3.2-fold) [51]. The trend throughout the western world as well as in most other parts of the world is that height is increasing in both women and men [52]. However, no significant changes were observed in young women, but height was seen to have increased in middle-aged women. These results may be attributed to the higher proportion of women born in countries other than Spain, mainly young women (5 \% in 1999-2000 and $15.1 \%$ in 2009-2010; data not shown). On the other hand, although some previous studies have associated migration with obesity [53, 54] and cardiovascular risks $[55,56]$, no trend in excess weight linked to origin was found in this study. Low social support, stress, the price and size of meals and shopping, cooking and eating habits are all linked to higher excessive weight in the foreign population [57]. However, literature also links migration to a protective effect against the risk of obesity [58-60]. For example, in the USA, adult immigrants showed a lower tendency towards being overweight and obese than their USA-born counterparts [61], but there is a tendency 
Table 4 Results of binomial regressions of excessive weight prevalence by social and socioeconomic factors and survey period in middle-aged Balearic Islands' women (36-55 years-old) $)^{a, b, c}$

\begin{tabular}{|c|c|c|c|c|c|c|}
\hline & \multicolumn{2}{|c|}{ 1999-2000 (ENIB survey) } & \multicolumn{2}{|c|}{ 2000-2010 (OBEX survey) } & \multirow[b]{2}{*}{ Change in Prevalence (\%) } & \multirow[b]{2}{*}{$\begin{array}{l}P \text {-value for } \\
\text { interaction }\end{array}$} \\
\hline & $\mathrm{BMI} \geq 25 n(\%)$ & Adjusted OR (95\% Cl) & $\mathrm{BMI} \geq 25 n(\%)$ & Adjusted OR (95\% Cl) & & \\
\hline$n$ & $167(48.8)$ & & $117(46.4)$ & & & \\
\hline \multicolumn{7}{|l|}{ Educational profile } \\
\hline Low (including medium) & $158(94.9)$ & 1.00 (ref.) & $79(67.2)$ & 1.00 (ref.) & 1.00 (ref.) & \\
\hline High & $9(5.1)$ & $0.39(0.17,0.90)^{*}$ & $38(32.8)$ & $0.55(0.32,0.95)^{*}$ & $1.37(0.51,3.69)$ & 0.538 \\
\hline \multicolumn{7}{|l|}{ Professional profile } \\
\hline Unemployed & $61(50.9)$ & 1.00 (ref.) & $21(18.1)$ & 1.00 (ref.) & 1.00 (ref.) & \\
\hline Employed & $114(49.1)$ & $0.65(0.41,1.03)$ & $96(81.9)$ & $0.58(0.28,1.20)$ & $0.85(0.36,2.01)$ & 0.718 \\
\hline \multicolumn{7}{|l|}{ Origin } \\
\hline Spanish & $162(92.8)$ & 1.00 (ref.) & $100(85.2)$ & 1.00 (ref.) & 1.00 (ref.) & \\
\hline Non-Spanish & $13(7.2)$ & $1.09(0.48,2.50)$ & $117(14.8)$ & $1.97(0.87,4.48)$ & $1.71(0.54,5.45)$ & 0.366 \\
\hline \multicolumn{7}{|l|}{ Cohabitation } \\
\hline Living alone & $8(6.0)$ & 1.00 (ref.) & $12(10.3)$ & 1.00 (ref.) & 1.00 (ref.) & \\
\hline Married or cohabiting & $167(94.0)$ & $0.68(0.25,1.81)$ & $105(89.7)$ & $1.11(0.49,2.48)$ & $1.76(0.50,6.22)$ & 0.382 \\
\hline \multicolumn{7}{|c|}{ Living with at least one child at home } \\
\hline None & $31(25.7)$ & 1.00 (ref.) & $42(35.9)$ & 1.00 (ref.) & 1.00 (ref.) & \\
\hline Yes & $144(74.3)$ & $0.74(0.43,1.26)$ & $75(64.1)$ & $0.78(0.45,1.35)$ & $1.02(0.47,2.019)$ & 0.964 \\
\hline
\end{tabular}

for this protective effect to dissipate depending on the length of stay $[60,62]$ when the risk of excessive weight increases $[54,60,63,64]$.

\section{Family and marital status}

Although no trend towards excesive weight linked to family and marital status was found in this study, it has previously been reported in literature that unmarried subjects are less likely to have excessive weight than married subjects [65-69]. The mechanism that links marital status and excessive weight is not so clear. It may well be due to the social obligations of marriage or a lack of concern about being attractive, which is particularly common among women. Nevertheless, literature has also previously reported that eating as a family protects young people and adults against obesity [70].

\section{Strengths and limitations}

A major methodological strength of this study is the anthropometric method used to obtain weight and height, which were measured by trained personnel. The interaction between the survey period and socioeconomic factors on excessive weight prevalence were assessed by binary logistic regression analyses applying the hierarchy principle (i.e. including the survey period, the socioeconomic factor and also the survey socioeconomic factor in the models) and only adjusted by age (continuous variable). Nevertheless, the use of large data sets is a major strength of this study.

The study also has several limitations which should be taken into consideration when interpreting its findings. Firstly, the cross-sectional designs provided no basis for studying causality. Longitudinal data would provide a more valid and reliable estimate of the prevalence of excessive weight. Secondly, the unemployed category was heterogeneous and more detailed information would have been beneficial to the study. Thirdly, there are few explanatory variables in this study with, for example, no exploration of physical activity levels or dietary behaviour.

\section{Conclusion}

To sum up, no significant increase in the prevalence of overweight/obesity was observed among middle-aged women and a low level of education was the single socioeconomic variable associated with excessive weight in this target group. In contrast, a significant increase in the prevalence of excessive weight was observed in young women and the single socioeconomic variable associated with this increase was unemployment. Factors relating to differences in the rate of increase of excessive weight in adult women will need further research. 


\section{Abbreviations}

ENIB survey: Balearic Islands' Nutritional Survey; OBEX survey: "Prevalence of Obesity in the Balearic Islands: their relationship with oxidative stress and inflammatory mediators" study; BMl: Body mass index; OR: Odds ratio; Cl: Confidence interval; UI: Uncertainty interval.

\section{Competing interests}

The authors declare that they have no competing interests.

\section{Authors' contributions}

MMB, AP and JAT conceived, designed, devised and supervised the study. $M M B, J L C$ and RS collected and supervised the samples. MMB, JLC and JAT analysed the data and wrote the manuscript. All the authors read and approved the final manuscript.

\section{Acknowledgements}

Spanish Ministry of Health and Consumption Affairs (Projects 05/1276, 08/1259, 11/01791, 14/00636, Red Predimed-RETIC RD06/0045/1004, and CIBEROBN CB12/03/30038), Grant of support to research groups no. 35/2011 (BI Gov.) and EU FEDER funds. Spanish Ministry of Education and Science (FPU Programme, PhD fellowship to M.M.B.). The Research Group on Community Nutrition and Oxidative Stress belongs to the Centre Català de la Nutrició and Exernet Network.

\section{Author details}

'Research Group on Community Nutrition and Oxidative Stress, University of Balearic Islands, IdISPa, and CIBEROBN (Physiopathology of Obesity and Nutrition CB12/03/30038), Guillem Colom Bldg, Campus, E-07122 Palma de Mallorca, Spain. ${ }^{2}$ Faculty of Public Health Nutrition, Autonomous University of Nuevo León, 64460 Monterrey, Mexico.

\section{Received: 25 February 2015 Accepted: 27 August 2015} Published online: 02 September 2015

\section{References}

1. Rokholm B, Baker JL, Sørensen TI. The levelling off of the obesity epidemic since the year 1999-a review of evidence and perspectives. Obes Rev. 2010;11:835-46.

2. World Health Organization. 2014. Available at http://www.who.int/ mediacentre/factsheets/fs311/en/. Accessed January 15, 2015.

3. Mokdad AH, Bowman BA, Ford ES, Vinicor F, Marks JS, Koplan JP. The continuing epidemics of obesity and diabetes in the United States. JAMA. 2001;286:1195-200.

4. Zaninotto P, Head J, Stamatakis E, Wardle H, Mindell J. Trends in obesity among adults in England from 1993 to 2004 by age and social class and projections of prevalence to 2012. J Epidemiol Community Health. 2009;6:140-6.

5. Dastgiri S, Mahdavi R, TuTunchi H, Faramarzi E. Prevalence of obesity, food choices and socioeconomic status: a cross-sectional study in the north-west of Iran. Public Health Natur. 2006:9:996-1000.

6. Mokdad AH, Ford ES, Bowman BA, Dietz WH, Vinicor F, Bales VS, et al. Prevalence of obesity, diabetes, and obesity-related health risk factors, 2001. JAMA. 2003;289:76-9.

7. Leung J, Burke B, Ford D, Garvin G, Korn C, Sulis C, et al. Possible association between obesity and Clostridium difficile infection. Emerg Infect Dis. 2013;19:1791-8.

8. Dee A, Kearns K, O'Neill C, Sharp L, Staines A, O'Dwyer V, et al. The direct and indirect costs of both overweight and obesity: a systematic review. BMC Res Notes. 2014;16:242.

9. Keaver L, Webber L, Dee A, Shiely F, Marsh T, Balanda K, et al. Application of the UK foresight obesity model in Ireland: the health and economic consequences of projected obesity trends in Ireland. PLoS One. 2013;8:e79827.

10. An R. Prevalence and trends of adult obesity in the US, 1999-2012. ISRN Obes. 2014;2014:185132.

11. Howel D, Stamp E, Chadwick TJ, Adamson AJ, White M. Are social inequalities widening in generalised and abdominal obesity and overweight among English adults? PLoS One. 2013;8:e79027.

12. Caballero B. The global epidemic of obesity: an overview. Epidemiol Rev. 2007;29:1-5.

13. McLaren L. Socioeconomic status and obesity. Epidemiol Rev. 2007;29:29-48.
14. Bibiloni MM, Salas R, Coll JL, Pons A, Tur JA. Ten-year trends in compliance with the current Spanish nutritional objectives in Balearic Islands adult population (2000-2010). Nutrition. 2014;30:800-6.

15. Costa-Font J, Hernández-Quevedo C, Jiménez-Rubio D. Income inequalities in unhealthy life styles in England and Spain. Econ Hum Biol. 2014;13:66-75.

16. Costa-Font J, Gil J. Are there Socio-Economic Inequalities in Obesity in Spain? Madrid: FEDEA, 2005. Available at http://documentos.fedea.net/pubs/ eee/eee217.pdf. Accessed January 15, 2015.

17. Cohen AK, Rai M, Rehkopf DH, Abrams B. Educational attainment and obesity: a systematic review. Obes Rev. 2013;14:989-1005.

18. García-Goñi M, Hernández-Quevedo C. The evolution of obesity in Spain. Eurohealth. 2012;18:22-5.

19. Tur JA, Romaguera D, Pons A. Adherence to the Mediterranean dietary pattern among the population of the Balearic Islands. Br J Nutr. 2004;92(3):341-6.

20. Tur JA, Romaguera D, Pons A. Does the diet of the Balearic population, a Mediterranean-type diet, ensure compliance with nutritional objectives for the Spanish population? Public Health Nutr. 2005;8(3):275-83.

21. Salas R, Bibiloni MM, Zapata ME, Coll JL, Pons A, Tur JA. Balearic adults have low intakes of fruits and vegetables compared with the dietary guidelines for adults in Spain. Nutr Res. 2013;33(3):204-10

22. Coll JL, Bibiloni MM, Salas R, Pons A, Tur JA. Prevalence and related risk factors of overweight and obesity among the adult population in the Balearic Islands, a Mediterranean Region. Obes Facts. 2015;8(3):220-33.

23. Stevens GA, Singh GM, Lu Y, Danaei G, Lin JK, Finucane MM, et al. Global Burden of Metabolic Risk Factors of Chronic Diseases Collaborating Group (Body Mass Index). National, regional, and global trends in adult overweight and obesity prevalences. Popul Health Metr. 2012;10:22.

24. Ng M, Fleming T, Robinson M, Thomson B, Graetz N, Margono C, et al. Global, regional, and national prevalence of overweight and obesity in children and adults during 1980-2013: a systematic analysis for the Global Burden of Disease Study 2013. Lancet. 2014;384:766-81.

25. Commission of the European Communities. Strategy for Europe on nutrition, overweight and obesityrelated health issues. 2007.http:// ec.europa.eu/health/ph_determinants/life_style/nutrition/documents/ nutrition_wp_en.pdf AccessedJanuary 16, 2015.

26. Salcedo V, Gutiérrez-Fisac JL, Guallar-Castillón P, Rodríguez-Artalejo F. Trends in overweight and misperceived overweight in Spain from 1987 to 2007. Int J Obes. 2010:34:1759-65.

27. Valera G, Silvestre D. Introducción [Introduction]. In Varela G, Silvestre D (eds) Obesidad en el S.XXI iqué se puede y se debe hacer? Obesity in the XXI century: what could and should be done? Madrid: International Marketing and Communication, 2009.

28. Aranceta-Bartrina A, Serra-Majem L, Foz-Sala M, Moreno-Esteban B, Grupo Colaborativo SEEDO. Prevalencia de Obesidad en España. Med Clin (Bar). 2005;125:460-6.

29. Rodriguez-Rodriguez E, López-Plaza B, López-Sobaler AM, Ortega RM. Prevalencia de Sobrepeso y Obesidad en adultos españoles. Nutr Hosp. 2011;26:355-63.

30. Cook A, Daponte B. A demographic analysis of the rise in the prevalence of the US population overweight and/or obese. Popul Res Policy Rev. 2008;27:403-26.

31. Berg C, Rosengren A, Aires N, Lappas G, Torén K, Thelle D, et al. Trends in overweight and obesity from 1985 to 2002 in Göteborg, West Sweden. Int J Obes (Lond). 2005;29:916-24.

32. Howel D. Trends in the prevalence of obesity and overweight in English adults by age and birth cohort, 1991-2006. Public Health Nutr. 2011;14:27-33.

33. Drieskens $\mathrm{S}$, Van der Heyden J, Demarest S, Tafforeau J. Is the different time trend (1997-2008) of the obesity prevalence among adults in the three Belgian regions associated with lifestyle changes? Arch Public Health. 2014;72:18.

34. Marques-Vidal P, Bovet P, Paccaud F, Chiolero A. Changes of overweight and obesity in the adult Swiss population according to educational level, from 1992 to 2007. BMC Public Health. 2010;10:87.

35. Roskam AJ, Kunst AE, Van Oyen H, Demarest S, Klumbiene J, Regidor E, et al. Comparative appraisal of educational inequalities in overweight and obesity among adults in 19 European countries. Int J Epidemiol. 2010;39:392-404.

36. Ford ES, Li C, Zhao G, Tsai J. Trends in obesity and abdominal obesity among adults in the United States from 1999-2008. Int J Obes (Lond). 2011;35:736-43.

37. Gutiérrez-Fisac JL, Regidor E, Banegas Banegas JR, Rodríguez AF. The size of obesity differences associated with educational level in Spain, 1987 and 1995/97. J Epidemiol Community Health. 2002;56:457-60. 
38. Arija V, Salas Salvadó J, Fernández-Ballart J, Cucó G, Martí-Henneberg C. Consumption, dietary habits and nutritional status of the Reus (IX) population. Evolution of food consumption, energy and nutrient intake and relationship with the socioeconomic and cultural level, 1983-1993. Med Clin (Barc). 1996;106:174-9.

39. Schröder H, Rohlfs I, Schmelz EM, Marrugat J, REGICOR investigators. Relationship of socioeconomic status with cardiovascular risk factors and lifestyle in a Mediterranean population. Eur J Nutr. 2004:43:77-85.

40. Paul Kl, Moser K. Unemployment impairs mental health: meta-analyses. J Vocat Behav. 2009;74:264-82.

41. McKee-Ryan FM, Son Z, Wanberg CR, Kinicki AJ. Psychological and physical well-being during unemployment: a meta-analytic study. J Appl Psychol. 2005;90:53-76

42. Roelfs DJ, Shor E, Davidson KW, Schwartz JE. Losing life and livelihood: a systematic review and meta-analysis of unemployment and all-cause mortality. Soc Sci Med. 2011;72:840-54.

43. Sarlio-Lätheenkorva S, Lahelma E. The association of body mass index with social and economic disadvantage in women and men. Int J Epidemiol. 1999:28:445-9.

44. Suhrcke M, Stuckler D, Suk JE, Desai M, Senek M, McKee M, et al. The impact of economic crises on communicable disease transmission and control: a systematic review of evidence. Plos ONE. 2009;6:e20724.

45. Stuckler D, Meissner C, King L. Can a bank crisis break our heart? Global Health. 2008;4:1.

46. Allman-Farinelli MA, Chey T, Merom D, Bauman AE. Occupational risk of overweight and obesity: an analysis of the Australian Health Survey. J Occup Med Toxicol. 2010;5:14

47. Galobardes B, Morabia A, Bernstein MS. The differential effect of education and occupation on body mass and overweight in a sample of working people of the general population. Ann Epidemiol. 2000;10:532-7.

48. Lopez-Arana S, Avendano M, van Lenthe FJ, Burdorf A. Trends in overweight among women differ by occupational class: results from 33 low- and middle-income countries in the period 1992-2009. Int J Obes (Lond). 2014;38:97-105.

49. Instituto Nacional de Estadística. Resultados Nacionales. Available at: http://www.ine.es/. Accessed on May 2015.

50. Organization for Economic Co-operation and Development (OECD). Education at a Glance 2013: OECD Indicators. Available at: http://www.oecd.org/ edu/eag2013\%20(eng)-FINAL\%2020\%20June\%202013.pdf. Accessed on: June 2015

51. Consell Econòmic i Social de les Illes Balears. Memoria del CES sobre la economía, el trabajo y la sociedad de las Islas Baleares, 2010. Available at: http://ces.caib.es/www/cd_memoria2010/data/menu_castellano.html. Accessed January 15, 2015.

52. Roser M. Human Height. Available at: http://ourworldindata.org/data/foodagriculture/human-height/ Accessed July 1, 2015.

53. Kandula NR, Diez-Roux AV, Chan C, Daviglus ML, Jackson SA, Ni H, et al. Association of acculturation levels and prevalence of diabetes in the multiethnic study of atherosclerosis (MESA). Diabetes Care. 2008;31:1621-8.

54. Gordon-Larsen P, Harris KM, Ward DS, Popkin BM. Acculturation and overweight-related behaviors among Hispanic immigrants to the US: the National Longitudinal Study of Adolescent Health. Soc Sci Med. 2003;57:2023-34

55. Sundquist J, Winkleby MA. Cardiovascular risk factors in Mexican American adults: a transcultural analysis of NHANES III, 1988-1994. Am J Public Health. 1999;89:723-30.

56. Koya DL, Egede LE. Association between length of residence and cardiovascular disease risk factors among an ethnically diverse group of United States immigrants. J Gen Intern Med. 2007;22:841-6.

57. Tovar A, Must A, Metayer N, Gute DM, Pirie A, Hyatt RR, et al. Immigrating to the US: What Brazilian, Latin American and Haitian women have to say about changes to their lifestyle that may be associated with obesity. J Immigr Minor Health. 2013;15:357-64.

58. Bennett GG, Wolin KY, Askew S, Fletcher R, Emmons KM. Immigration and obesity among lower income blacks. Obesity (Silver Spring). 2007;15:1391-4.

59. Mejean C, Traissac P, Eymard-Duvernay S, El Ati J, Delpeuch F, Maire B. Influence of socioeconomic and lifestyle factors on overweight and nutrition-related diseases among Tunisian migrants versus non-migrant Tunisians and French. BMC Publ Health. 2007;7:265.

60. Singh GK, Siahpush M, Hiatt RA, Timsina LR. Dramatic increases in obesity and overweight prevalence and body mass index among ethnic-immigrant and social class groups in the United States, 1976-2008. J Community Health. 2011;36:94-110.

61. Renzaho AM, Mellor D, Boulton K, Swinburn B. Effectiveness of prevention programmes for obesity and chronic diseases among immigrants to developed countries - a systematic review. Public Health Nutr. 2010;13:438-50.

62. Goel MS, McCarthy EP, Phillips RS, Wee CC. Obesity among US immigrant subgroups by duration of residence. JAMA. 2004;292:2860-7.

63. Akresh IR. Dietary assimilation and health among Hispanic immigrants to the United States. J Health Soc Behav. 2007;48:404-17.

64. Sanchez-Vaznaugh EV, Kawachi I, Subramanian SV, Sanchez BN, AcevedoGarcia D. Differential effect of birthplace and length of residence on body mass index (BMI) by education, gender and race/ethnicity. Soc Sci Med. 2008:67(8):1300-10.

65. Sobal J, Stunkard AJ. Socioeconomic status and obesity: a review of the literature. Psychol Bull. 1989;105:260-75.

66. Martinez JA, Kearney JM, Kafatos A, Paquet S, Martinez-Gonzalez MA. Variables independently associated with self-reported obesity in the European Union. Public Health Nutr. 1999;2:125-33.

67. Tur JA, Serra-Majen L, Romaguera PA. Profile of overweight and obese people in a Mediterranean region. Obes Res. 2005;13:527-36.

68. Roshania R, Narayan KM, Oza-Frank R. Age at arrival and risk of obesity among US immigrants. Obesity (Silver Spring). 2008;16:2669-75.

69. Janghorbani M, Amini M, Rezvanian H, Gouya MM, Delavari A, Alikhani S, et al. Association of body mass index and abdominal obesity with marital status in adults. Arch Iran Med. 2008;11:274-81.

70. Harris KM, Lee H, De Leone FY. Marriage and health in the transition to adulthood: evidence for African Americans in the add health study. J Fam Issues. 2010;31:1106-43.

\section{Submit your next manuscript to BioMed Central and take full advantage of:}

- Convenient online submission

- Thorough peer review

- No space constraints or color figure charges

- Immediate publication on acceptance

- Inclusion in PubMed, CAS, Scopus and Google Scholar

- Research which is freely available for redistribution 